\title{
Development of roughness updating based on artificial neural network in a river hydraulic model for flash flood forecasting
}

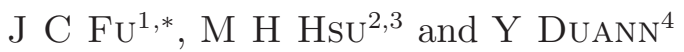 \\ ${ }^{1}$ National Science \& Technology Center for Disaster Reduction, New Taipei 23143, Taiwan (ROC). \\ ${ }^{2}$ Department of Civil and Disaster Prevention Engineering, National United University, Miao-Li 36003, \\ Taiwan (ROC). \\ ${ }^{3}$ Department of Bioenvironmental Systems Engineering, National Taiwan University, Taipei 10006, \\ Taiwan (ROC). \\ ${ }^{4}$ Department Institute of Civil Engineering and Hazard Mitigation Design, China University of Technology, \\ Taipei 11695, Taiwan (ROC). \\ ${ }^{*}$ Corresponding author.e-mail: jcfu@ncdr.nat.gov.tw
}

Flood is the worst weather-related hazard in Taiwan because of steep terrain and storm. The tropical storm often results in disastrous flash flood. To provide reliable forecast of water stages in rivers is indispensable for proper actions in the emergency response during flood. The river hydraulic model based on dynamic wave theory using an implicit finite-difference method is developed with river roughness updating for flash flood forecast. The artificial neural network (ANN) is employed to update the roughness of rivers in accordance with the observed river stages at each time-step of the flood routing process. Several typhoon events at Tamsui River are utilized to evaluate the accuracy of flood forecasting. The results present the adaptive $n$-values of roughness for river hydraulic model that can provide a better flow state for subsequent forecasting at significant locations and longitudinal profiles along rivers.

\section{Introduction}

Flood forecasting has been an efficient tool for providing early warning to mitigate the risk of damage from flash floods. In several countries, the technological and procedural improvements have been made to provide early warning message in support of emergency operation and evacuation. However, there are still many possibilities to improve the accuracy and computation efficiency of the forecast.

Applications of data assimilation techniques (such as input updating, state updating, parameter updating and output updating) and the real-time monitoring data arise in the field of real-time flood forecasting to present an actual state of the system which can get better results of forecast (Sene 2013). For example, Liu et al. (2010), Khatibi et al. (2011) and Park and Markus (2014) used monitored data (such as daily precipitation, temperature, and river flow observation) to improve the accuracy of flood modelling with the data assimilation that is available for flood forecasting. However, simulation errors were not completely eliminated due to the uncertainties existed in parameters, structure and boundary conditions of such model. Therefore, several data assimilation methods had been utilized to filter the problems, one of which will be used herein for updating model states (such as water stage and flow) with observations (Hsu et al. 2010; Weerts et al. 2011; Neal et al. 2012; Leedal et al. 2013;

Keywords. Hydraulic routing; flash flood forecasting; roughness updating; artificial neural network; Tamsui River. 
Li et al. 2014). Numerous works have been done to prevent a gradual reduction of the achieved improvement due to lack of parameter updating. Hsu et al. (2006) used observed water stages to update the roughness of forecasting model based on the assumption of gradual and varied flow in forecasting. Song et al. (2011) found that the flood routing method with variable parameters presented the relative error of peak discharge less than $20 \%$ and runoff volume less than $10 \%$ in the Louzigou Basin of China. Chen et al. (2013) integrated the Ensemble Square-Root-Filter for parameter optimization into a hydrological model to improve realtime streamflow forecasting. Karahan et al. (2013) used a hybrid harmony search algorithm to estimate the parameters of the nonlinear Muskingum model.

The purpose of this work is to evaluate the potential of a river hydraulic model for the real-time forecasting of flash floods with updating the model parameters. Hydraulic model of a river is based on dynamic wave theory and an implicit finitedifference method is utilized to provide flood warning information for any desired cross-section of rivers. The artificial neural network (ANN) is used to find a simple and efficient roughness updating function that the adaptive Manning's $n$ at each time-step of the flood routing process can be determined by using the previous-time computed flows and observed water stages. The river hydraulic model with adaptive parameters will be run to obtain a better forecasting result that is close to observed flow data.

\section{Model}

\subsection{River hydraulic model}

Hydraulic model of the river is based on the dynamic wave theory of Saint-Venant equations which are continuity and momentum equations that describe one-dimensional gradual and varied flow. These equations are found as follows (Chow et al. 1998):

$$
\begin{gathered}
\frac{\partial A}{\partial t}+\frac{\partial Q}{\partial x}-q_{1}+q_{2}=0 \\
\frac{\partial Q}{\partial t}+\frac{\partial}{\partial x}\left(\frac{Q^{2}}{A}\right)-g A\left(S_{o}-\frac{\partial Y}{\partial x}-S_{f}\right) \\
-q_{1} V_{1}+q_{2}\left(\frac{Q}{A}\right)=0
\end{gathered}
$$

where $A$ is cross-sectional area; $Y$ the water depth; $Q$ the discharge; $q_{1}$ the lateral inflow per unit channel length; $q_{2}$ the lateral outgoing overflow per unit channel length; $S_{o}$ the channel bottom slope; $S_{f}$ the friction slope; $V_{1}$ the longitudinal velocity component of lateral inflow; $g$ the gravitational acceleration; $t$ the time; and $x$ the distance along the channel. Since the cross-sectional area can be written as a function to water depth, only two flow variables, $Q$ and $Y$, have to be solved in equations (1 and 2).

Equations (1 and 2) can be solved if the suitable initial and boundary conditions are prescribed. In this work, the four-point implicit finite-difference approximation (Preissman 1961Amein and Fang 1970) is used to solve the equations. During the process of discretization, the two adjoining crosssections can be organized into two equations with four unknown flow variables at the advanced time.

$$
\begin{aligned}
& C_{\ell}\left(Q_{\ell+1}^{t+1}, Y_{\ell+1}^{t+1}, Q_{\ell}^{t+1}, Y_{\ell}^{t+1}, Q_{\ell+1}^{t}, Y_{\ell+1}^{t}, Q_{\ell}^{t}, Y_{\ell}^{t}\right) \\
& \quad=0 \\
& \quad M_{\ell}\left(Q_{\ell+1}^{t+1}, Y_{\ell+1}^{t+1}, Q_{\ell}^{t+1}, Y_{\ell}^{t+1}, Q_{\ell+1}^{t}, Y_{\ell+1}^{t}, Q_{\ell}^{t}, Y_{\ell}^{t}\right) \\
& \quad=0
\end{aligned}
$$

where $C_{\ell}$ and $M_{\ell}$ are the discretized continuity and momentum equations between $\ell$ th and $(\ell+1)$ th cross-sections, respectively. The subscript $\ell$ denotes cross-sectional index for $1,2, \ldots, L$, numbering from upstream to downstream, and $t$ and $(t+1)$ are the present and advanced times, respectively.

For a river with $L$ cross-sections, a system of $(2 L-2)$ equations with $2 L$ unknown flow variables are obtained. The deficiency in the number of equations is compensated by boundary conditions, which are used to solve for the unknowns. The boundary conditions of the dynamic flood routing model are the discharges upstream and the tide stages at the mouth of river. The nonlinear equations are solved using Newton's iteration and the Gaussian elimination methods.

Manning friction coefficients are components of the friction slope $\left(S_{f}\right)$ term for the resistance and flow variables from the Manning's formula

$$
S_{f}=\frac{n^{2} Q|Q|}{R^{4 / 3} A^{2}}
$$

where $R$ is the hydraulic radius and $n$ denotes the roughness of Manning friction coefficient.

A fixed Manning's $n$ may yield poor performance in time-varying dynamic flood routing processes. Following the advances in transmission technology, real-time observed water stages are obtained from gauge stations and provided new flow information that yields the optimal estimate of Manning's $n$. In the work, an ANN is used to update Manning's $n$ at each time-step of the flood routing processes in the dynamic flood routing model to ensure that the computed water stages are consistent with observations.

\subsection{Updating roughness based on ANN}

An ANN is a parallel computing system which is based on the structure and function of the brain; 
it is also a computational methodology for solving problems by applying information that has been gained from past experience to new problems and scenarios. Among the many ANN architectures, the multi-layer perception architecture is commonly applied to make predictions. And a supervised learning algorithm is frequently used to teach the networks how to input node patterns that are related to output nodes (Chen et al. 2013; Ryszard et al. 2014; Uzlu et al. 2014). One hidden layer is used herein to prevent the ANN from falling into bad local minima (Villiers and Barnard 1992). Figure 1 displays the structure of an ANN that consists of nodes and connections that are organized in three layers, i.e., the input layer, the hidden layer, and the output layer.

The ANN architecture generally has $I$ input nodes in the input layer, and node $j$ in a hidden layer that receives information from every node $i$ in the input layer. A weight $\left(W_{i j}^{H}\right)$ and biases $\left(\theta_{i j}^{H}\right)$ link each input node $\left(X_{i}\right)$ to node $j$ so that the effective incoming information $\left(H_{j}\right)$ to node $j$ is a weighed sum of all incoming information

$$
H_{j}=\sum_{i=1}^{I} W_{j i}^{H} X_{i}+\theta_{j}^{H}
$$

where $W_{j i}^{H}$ and $\theta_{j}^{H}$ are the weights and biases between the two respective adjoining layers.
The effective input, $H_{j}$, is passed through a transfer function to generate the outgoing value of the node. This transfer function can introduce nonlinearity into ANN models. Commonly used transfer functions include linear, sigmoid, and hyperbolic tangent functions. Of these three types, the steadily increasing $S$-sigmoid function is the most frequently used (Haykin 1999), and the function values of $S$-sigmoid are bounded within the range $[0,1]$ (Xu and Li 2002). The $S$-sigmoid function is expressed mathematically as:

$$
f\left(H_{j}\right)=\frac{1}{1+\exp \left(-H_{j}\right)} .
$$

Mathematically, a three-layered ANN with $I$ input nodes, $J$ hidden nodes, and $K$ output nodes can be expressed as:

$$
\begin{aligned}
n_{k}= & f\left(\sum_{j=1}^{J}\left(W_{k j}^{O} \cdot f\left(H_{j}\right)\right)+\theta_{k}^{O}\right) \\
= & \frac{1}{1+\exp \left(-\sum_{j=1}^{J} W_{k j}^{o}\right.} \\
& \left.\times\left(1 /\left(1+\exp \left(-\sum_{i=1}^{I} W_{j i}^{H} X_{i}-\theta_{j}^{H}\right)\right)\right)-\theta_{k}^{o}\right)
\end{aligned}
$$

where $n_{k}$ denotes outputs from the network, and $W_{k j}^{O}$ and $\theta_{k}^{O}$ are the weights and biases linking the

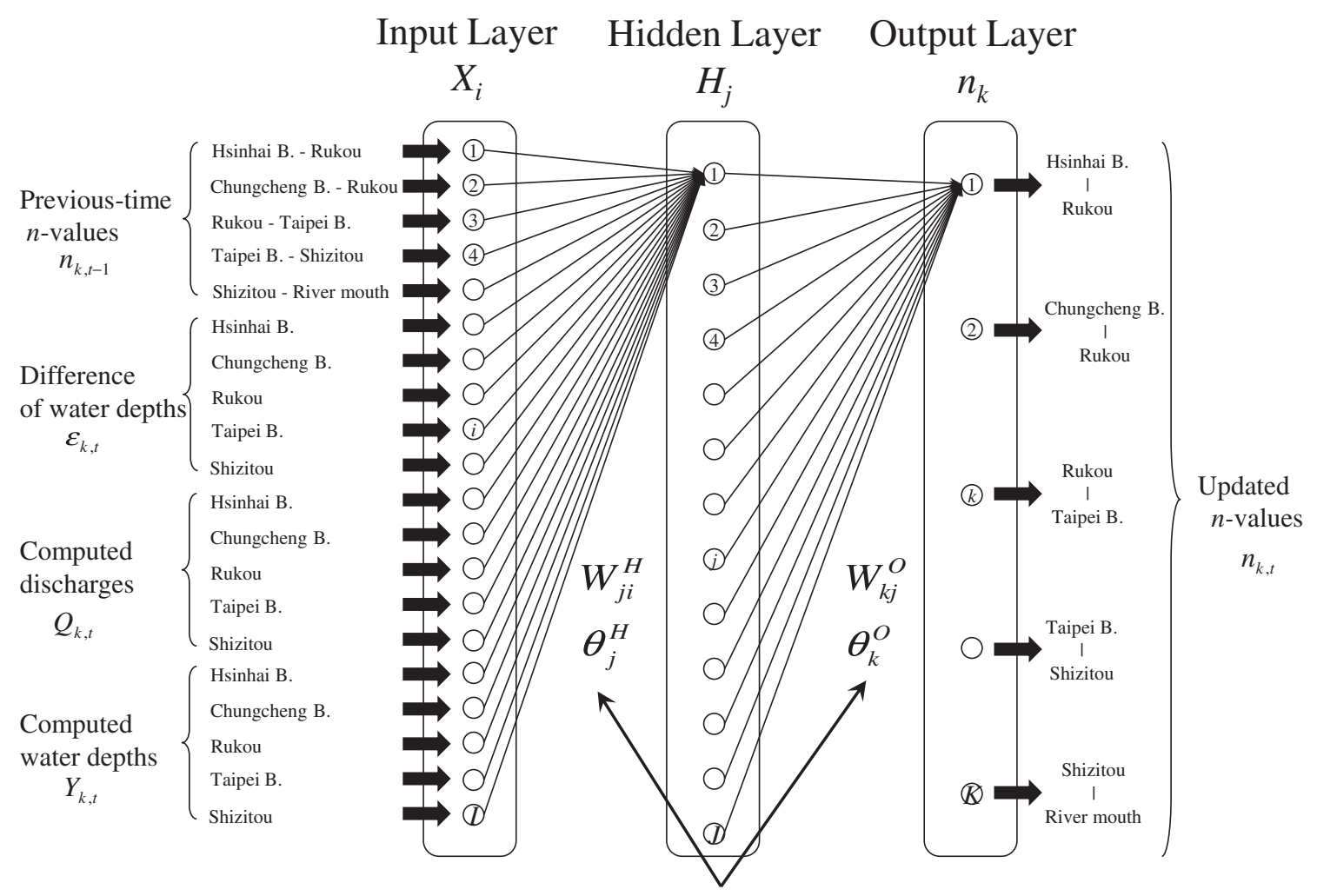

Connection weights and bias

Figure 1. Schematic of the artificial neural network configuration in the study. 
hidden nodes and output nodes. $i, j$, and $k$ represent the number of neurons for input layer, hidden layer, and output layer, respectively.

The weights $\left(W_{j i}^{H}, W_{k j}^{O}\right)$ and biases $\left(\theta_{j}^{H}, \theta_{k}^{O}\right)$, which specify the strengths of the connection among nodes, are initially set to arbitrary small values. When the model is trained, the weights and biases gradually converge to values that allow each input vector to generate output values as close as possible to the desired target output. The back-propagation (BP) algorithm with error minimization and ongoing training is applied to the nonlinear problem; the weights and biases are updated systematically, and the network output value is matched against the target output value (Rumelhart and Hinton 1986; Marier and Dandy 2000).

Updating of roughness in the hydraulic model of a river is a nonlinear and complex process. In this study, equation (8) of ANN is used to update roughness in real time. Initially, the differences of water depth, discharge, and previous $n$-value are taken as input variables to obtain new $n$-value. Several typhoon events are then considered to find the optimal weights $\left(W_{j i}^{H}, W_{k j}^{O}\right)$ and biases $\left(\theta_{j}^{H}, \theta_{k}^{O}\right)$ in equation (8). The following section will elaborate the combination of the flood routing model with the ANN.

\subsection{Solution of combination with river hydraulic model and ANN}

In this study, Manning's $n$ value was modified with reference to water stages that were obtained from the monitoring and transmission system, and roughness was updated to revise Manning's $n$ values. The recalculated water stage profile with the new Manning's $n$ may match the observed water stages in real time. In other words, the flood routing model uses the new Manning's $n$ and previous flow conditions to recalculate present flood conditions. Therefore, the discretized forms of the continuity and momentum equations for the present time and previous times are as follows:

$$
\begin{aligned}
& C_{\ell}\left(Q_{\ell+1}^{t}, Y_{\ell+1}^{t}, Q_{\ell,}^{t} Y_{\ell}^{t}, Q_{\ell+1}^{t-1}, Y_{\ell+1}^{t-1}, Q_{\ell}^{t-1}, Y_{\ell}^{t-1}\right) \\
& \quad=0 \\
& M_{\ell}\left(Q_{\ell+1}^{t}, Y_{\ell+1}^{t}, Q_{\ell}^{t}, Y_{\ell}^{t}, Q_{\ell+1}^{t-1}, Y_{\ell+1}^{t-1}, Q_{\ell}^{t-1}, Y_{\ell}^{t-1}\right) \\
& \quad=0
\end{aligned}
$$

Assume that the interior gauge stations are numbered $1,2,3, \ldots, K$ from upstream to downstream. The river can thus be split into $K$ river segments by the interior gauge stations, such that each river segment consists of several cross-sections. The segments have boundaries at gauge station or downstream boundary, and are used in simulating the model and updating roughness. The first river segment is located between the first and second gauge stations. The last river segment is located between the gauge station $K$ and the downstream boundary. All cross-sections in one river segment are assumed to have the same $n$-value, so that $K$ segments can be used for updating roughness for the river system.

During a typhoon, when the computed river depths differ from the depths observed at gauge stations, the differences in water depths can be reduced by using the depths that is recalculated using the updated values of Manning's $n$. This work uses ANN that updates Manning's $n$ in terms of flow conditions and observed depths in rivers. If the ANN has one hidden layer and a sigmoid function, then the performance function can be redefined, and the new $n$-values $\left[n_{k}\right]_{m}$ can be obtained from $\left[n_{k}\right]_{m-1}$ as follows:

$$
\begin{aligned}
{\left[n_{k}\right]_{m}=} & \frac{1}{1+\exp \left(-\sum_{j=1}^{J} W_{k j}^{O}\right.} \\
& \left.\times\left(1 /\left(1+\exp \left(-\sum_{i=1}^{I} W_{j i}^{H} X_{i}-\theta_{j}^{H}\right)\right)\right)-\theta_{k}^{O}\right)
\end{aligned}
$$

where the subscript $m$ is iteration number, and $I$, $J$, and $K$ are the number of neurons for input layer, hidden layer, and output layer, respectively. $W_{j i}^{H}$ and $W_{k j}^{O}$ are the weights and biases between input and hidden layers, respectively. The weights and biases that link hidden nodes with output layers are derived from $W_{k j}^{O}$ and $\theta_{k}^{O}$, respectively. When the training method is used and typhoon events considered, the optimal weights $\left(W_{j i}^{H}, W_{k j}^{O}\right)$ and biases $\left(\theta_{j}^{H}, \theta_{k}^{O}\right)$ can be obtained. The term $X_{i}$ which consists of input variables, is the $n$-values at a previous time, the difference between the computed and observed water depths, the computed discharges, and the computed depths from gauge stations at the present time.

The roughness is updated iteratively to reduce error in the calculated water depth when the computed water stages and the observed values at the gauge stations differ from each other. Figure 2 presents the procedure for dynamic flood routing, which includes updating roughness using the ANN, and it presents the water stages that were measured at the gauge stations at present time with roughness updated to find the new Manning's $n$ values until the desired convergence criteria are satisfied. In this work, the convergence criteria are set as follows:

$$
\frac{\left|\left[n_{k}\right]_{m}-\left[n_{k}\right]_{m-1}\right|}{\left[n_{k}\right]_{m}}<0.01 .
$$

Now, the dynamic routing in advanced time can be computed by solving equations ( 3 and 4 ) with 


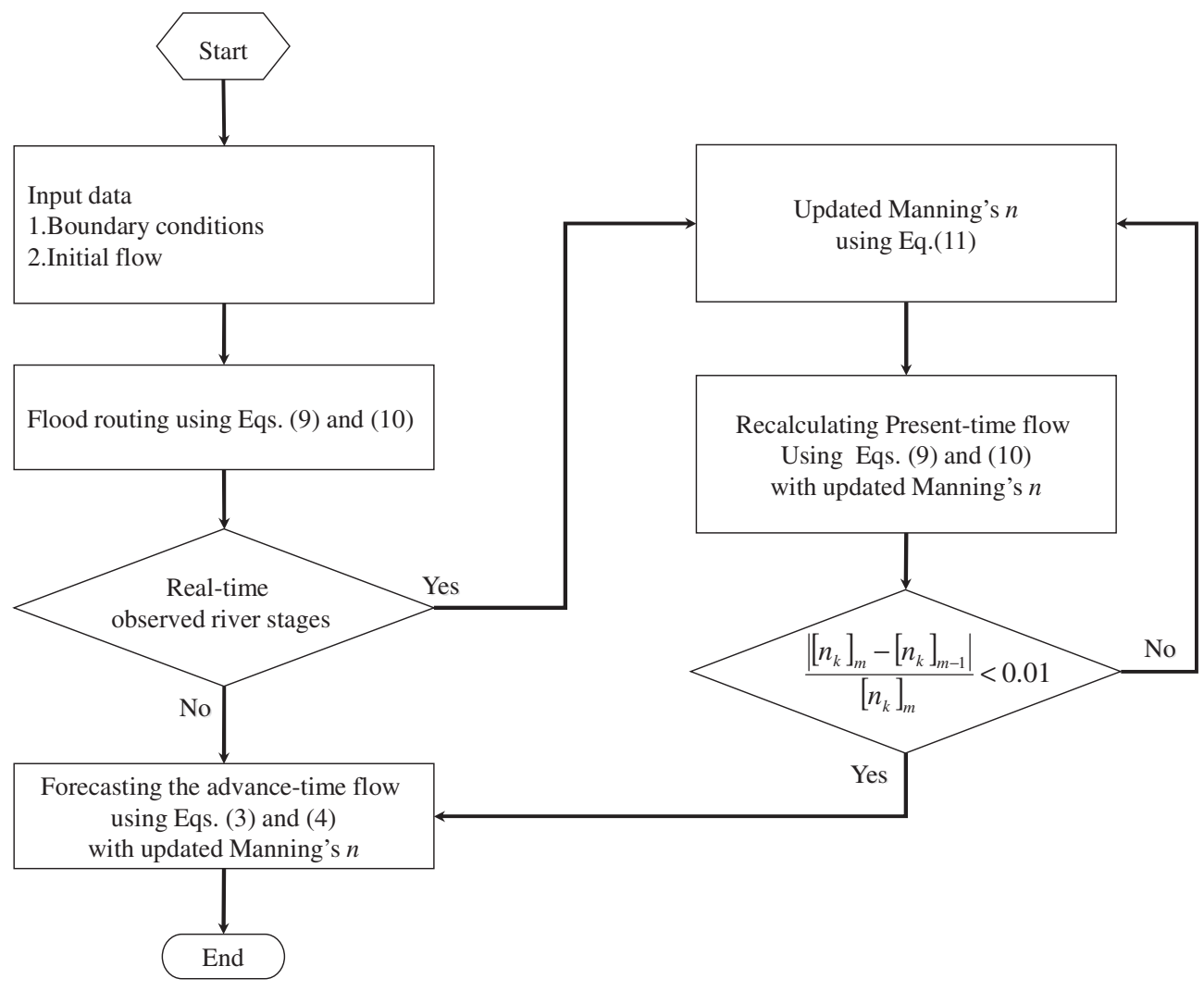

Figure 2. The procedures for flood routing and forecasting calculations.

the newly updated $n$-values. Since Manning's $n$ is a function of the computed water stage in the routing model, a reliable initialization of the water stage and flow at present time is carried out concurrently with the updating of Manning's $n$. Then, the dynamic routing model uses the adaptive Manning's $n$ to forecast riverflows.

\section{Site}

The above model is applied to Tamsui River basin that covers an area of $2726 \mathrm{~km}^{2}$ with a total channel length of $327.6 \mathrm{~km}$ at northern Taiwan. The river has three major tributaries: (1) Dahan River, (2) Xindian River, and (3) Keelung River. The downstream reach of each tributary is affected by tides, and the gradient of the channel ranges from $0.15 \%$ to $27 \%$. Metropolitan Taipei, with a population of about six million, is located at the estuarine portion of Tamsui River. The annual precipitation of the basin is around $3000 \mathrm{~mm}$. In Taiwan, about $70 \%$ of the rainfall occurs during monsoon and typhoon seasons from April to October. High precipitations, steep land slopes, and short river length usually lead to a very short time (3-6 hr) for floodwater convergence downstream, which results heavy losses of life and properties. The mean annual loss due to flash flood events in Taiwan is

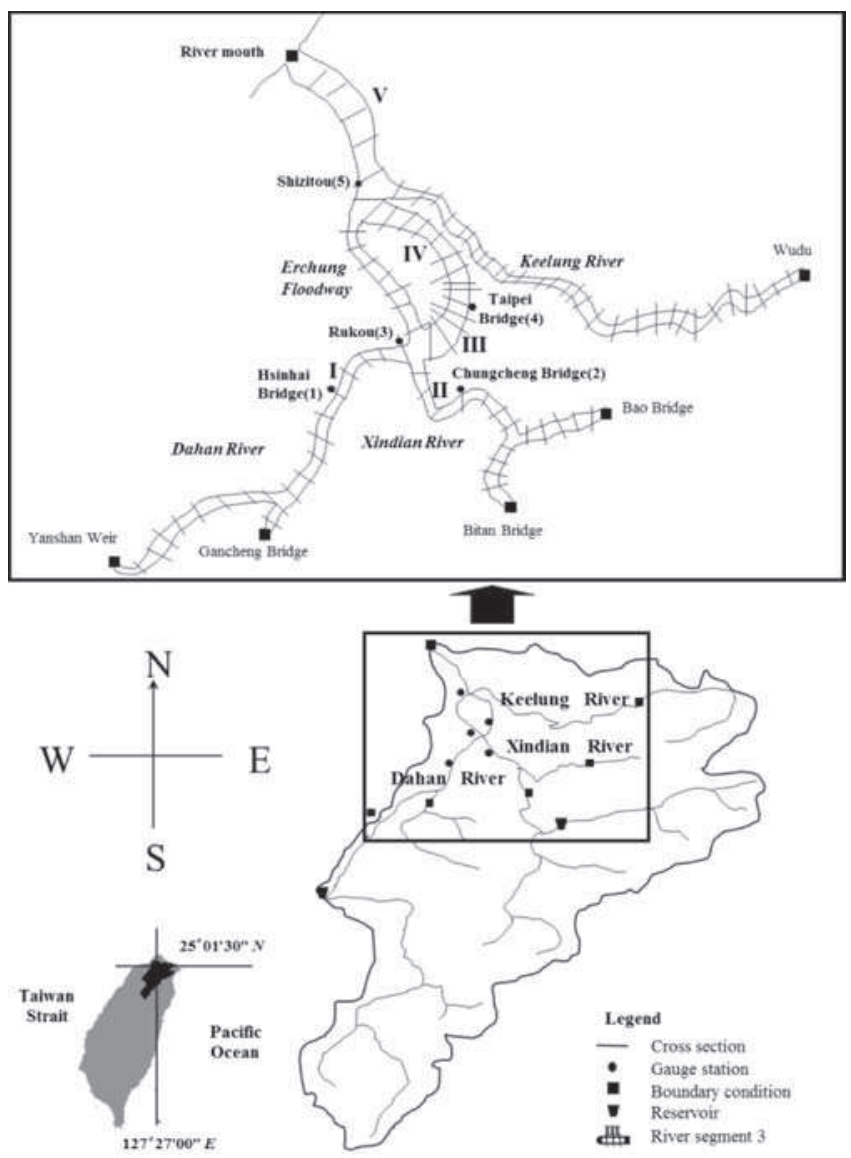

Figure 3. Map of the Tamsui River system. 
around US\$28.03 million. Therefore, effective flood risk management or mitigation in Taiwan is given very high priority.

To minimize flood damage, various flood control measures have been studied since 1960. The Taipei Flood Prevention Project, included the construction of levee along river, flood control reservoirs at the upstream basin, diversion channel, as well as channel improvement were studied. Finally, the proposed measure that combines the construction of Erchong Floodway located near the confluence of Dahan and Xindian rivers (figure 3 ), and a levee system along the riversides (totalling about $68,100 \mathrm{~m}$ ) were carried out. In addition, a flood forecast system based on storage function approach was applied

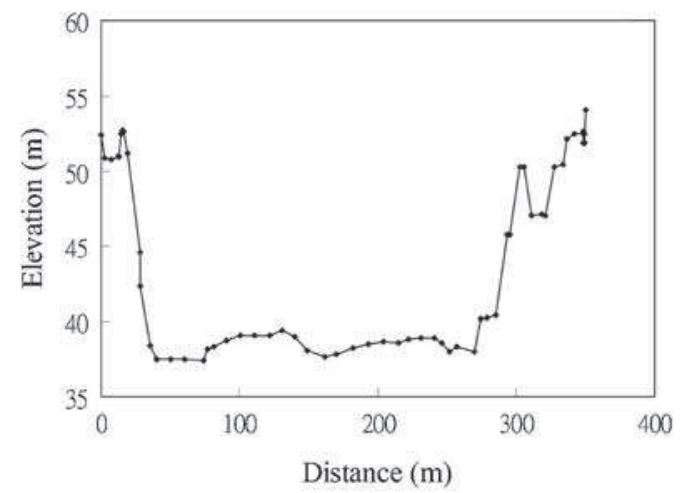

(a) Yanshan Weir (Tahan Creek)

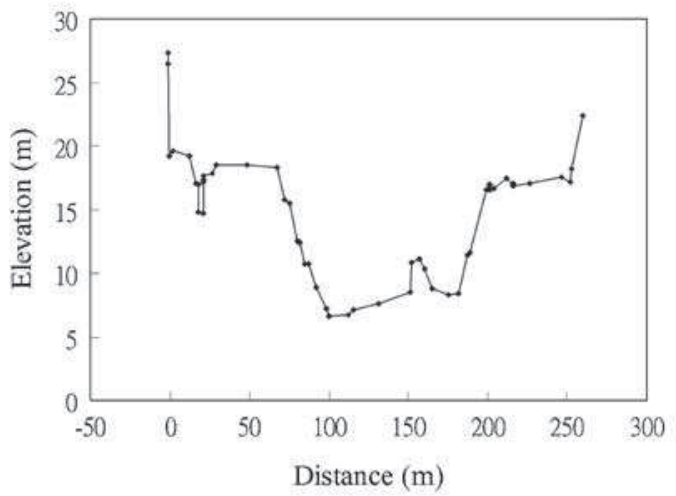

(b) Gancheng Bridge (Sanxia Creek)

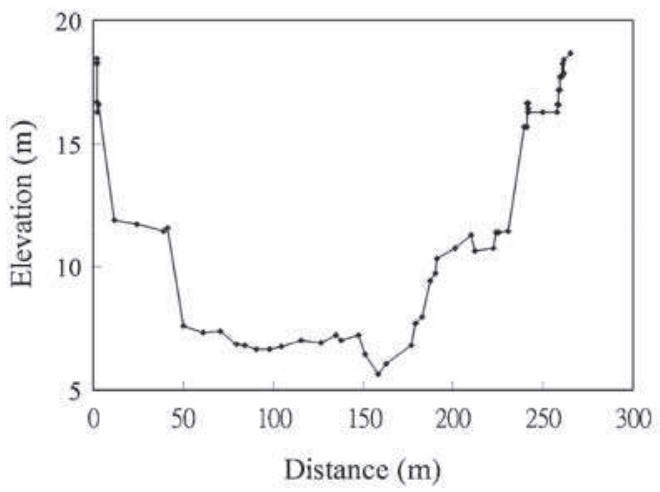

(c) Bitan Bridge (Hsintien Creek) to mitigate flood damage of Tamsui River basin in 1977. In 1998, the system was on upgrade to a real-time dynamic flood forecast system. In the system, the roughness of Manning's $n$ values was fixed during flood periods (Yen et al. 1998).

In this work, model transects are established using measured cross-sectional profiles at intervals of approximately $0.5 \mathrm{~km}$ along the river. Where the gauge stations are used as the dividing points, Tamsui River is split into five $n$-updating river segments, including Hsinhai Bridge-Rukou (first segment), Chungcheng Bridge-Rukou (second segment), Rukou-Taipei Bridge (third segment), Taipei Bridge-Shizitou (fourth segment), and ShizitouRiver mouth (fifth segment). Figure 3 displays the

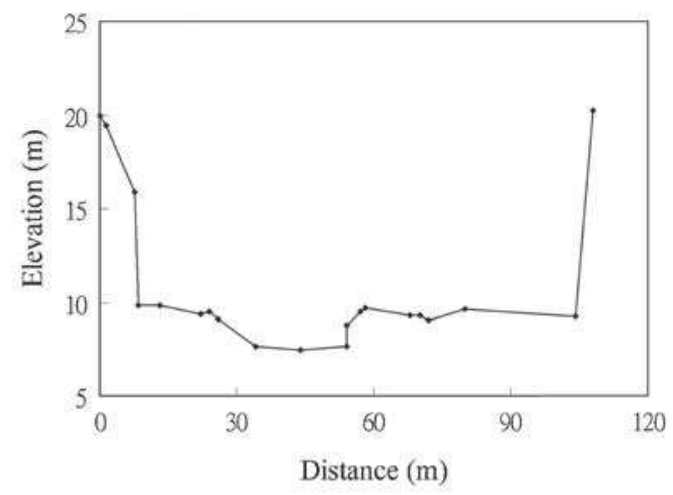

(d) Bao Bridge (Jingmei Creek)

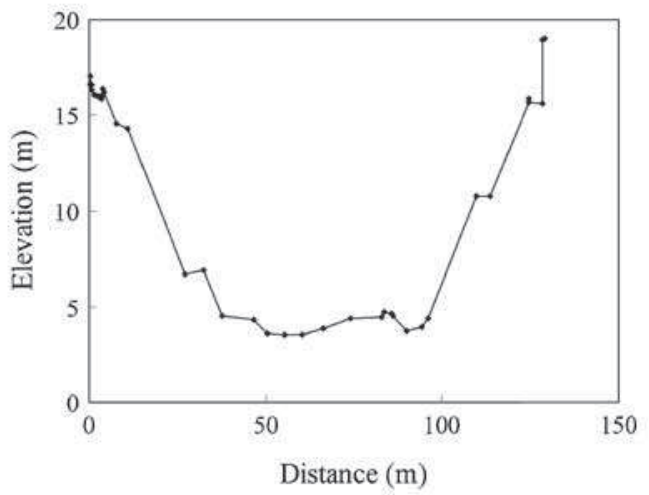

(e) Wudu (Keelung River)

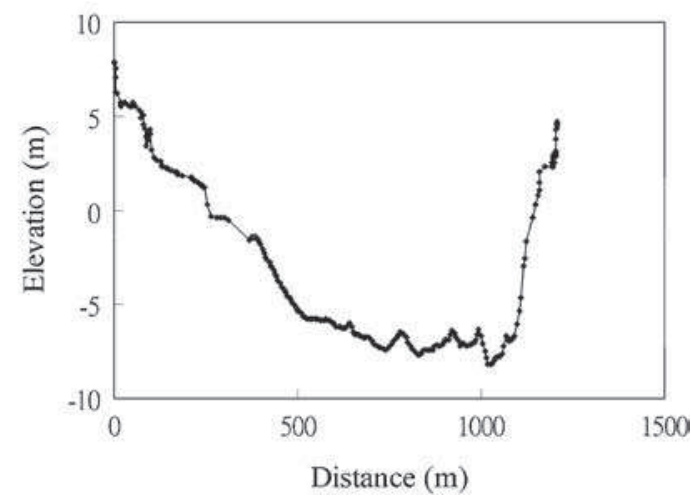

(f) River mouth (Tamsui River)

Figure 4. The typical cross-sections of Tamsui River. 
locations of these five gauge stations and river segments in Tamsui River system. Figure 3 also depicts the model transects at the computational domain and it includes 210 transects. The typical cross-sections of the Tamsui River are presented in figure 4 . The downstream boundary is set at the river mouth, and upstream boundaries specified at Yanshan Weir (Dahan River), Gancheng Bridge (Sanxia River), Bitan Bridge (Xindian River), Bao Bridge (Jingmei River), and Wudu (Keelung River). Imposed as interior boundary conditions that update Manning's $n$ in the river segments, these water stages are monitored every hour at the five gauge stations (i.e., Hsinhai Bridge, Chungcheng Bridge, Rukou, Taipei Bridge, and Shizitou).

\section{Results and discussion}

\subsection{Optimizing weight and bias using training method and typhoon events}

The objective of this section is to construct a network to achieve a desired nonlinear mapping regulated with a dataset that is made up of desired input-output pairs for a target system for the purposes of modelling. Restated, to find the unknown parameters, weights $\left(W_{j i}^{H}, W_{k j}^{O}\right)$ and biases $\left(\theta_{j}^{H}, \theta_{k}^{O}\right)$ in equation (11), experiments have to be carried out to obtain a training dataset of data pairs that are derived from the optimal number of hidden nodes, the learning rate, and the momentum factor. The set of training data represent the desired input-output pairs of the target system for modelling. Tamsui River system is divided into five $n$-updating river segments. The total number of inputs is 20; the inputs include the previous-time Manning's $n$ for the five river segments, as well as the difference of water depths, the computed discharge, and the computed water depths at the five river gauge stations (Hsinhai Bridge, Chungcheng Bridge, Rukou, Taipei Bridge, and Shizitou).

The individual optimal fixed Manning's $n$ values are calibrated with a trial-and-error method which targeted the computed water stages close to the observed values from the hydraulic model simulation of the typhoons events, taken from Yen et al.
(1998). The Manning's values were calibrated using the whole time series for the nine typhoon events, which are listed in table 1 . The table shows that the Manning's $n$ values are not consistent among the typhoon events. The mean calibrated Manning's $n$ values for the five river segments, Hsinhai BridgeRukou, Chungcheng, Bridge-Rukou, Rukou-Taipei Bridge, Taipei Bridge-Shizitou, and Shizitou-River mouth, were $0.033,0.032,0.030,0.023$, and 0.023 , respectively. The calibrated Manning coefficients are herein as initial values for updating the roughness and individual optimal values for the finding weights $\left(W_{j i}^{H}, W_{k j}^{O}\right)$ and biases $\left(\theta_{j}^{H}, \theta_{k}^{O}\right)$ in equation (11). Two typhoon events of Herb (1996) and Winnie (1997) were used to generate a series of data for ANN training. Several sets of Manning's $n$ and observed values through Typhoon Herb and Winnie were used in dynamic flood routing model to calculate the discharges, water depths, and difference between calculated and observed water depths as the input data in equation (11). The individual optimal Manning's $n$ values were taken as the target in equation (11). These calculations constitute around 1500 data which serve as the training data for the ANN model. The training dataset with several momentum factors, learning rate and node numbers of hidden layer was used in 100,000 iterations with the same initial state to find the optimal interconnecting weights and biases.

The neural network is based on a sigmoid function and one hidden layer, and the number of hidden nodes, learning rate, and momentum factor are determined by trial-and-error, based on the total error criterion (Bodri and Cermá 2000). The performance of the ANN initially improves as the number of intermediate nodes increases, but then declines beyond the optimal performance. This finding reveals that although the training process becomes progressively easier, the generalizability of the network reaches the optimum, and cannot be improved indefinitely by increasing the number of intermediate nodes. The mean squared error over the training samples is typically expressed as:

$$
\mathrm{MSE}=\frac{1}{K} \sum_{k=1}^{K}\left(n_{k}-\hat{n}_{k}\right)^{2}
$$

Table 1 . The roughness values calibrated by the nine typhoon events.

\begin{tabular}{lcccccccccc}
\hline & \multicolumn{1}{c}{ Manning's $n$} \\
\cline { 2 - 10 } River segment & Elsie & Bess & Betty & Billie & Vera & Ora & Nelson & Polly & Ted & Average \\
\hline Hsinhai Bridge-Rukou & 0.033 & 0.033 & 0.030 & 0.033 & 0.030 & 0.033 & 0.033 & 0.033 & 0.033 & 0.033 \\
Chungcheng Bridge-Rukou & 0.033 & 0.027 & 0.027 & 0.027 & 0.030 & 0.027 & 0.033 & 0.030 & 0.033 & 0.032 \\
Rukou-Taipei Bridge & 0.030 & 0.028 & 0.025 & 0.030 & 0.032 & 0.030 & 0.030 & 0.030 & 0.030 & 0.030 \\
Taipei Bridge-Shizitou & 0.023 & 0.020 & 0.025 & 0.030 & 0.025 & 0.020 & 0.020 & 0.030 & 0.020 & 0.023 \\
Shizitou-River mouth & 0.020 & 0.024 & 0.022 & 0.024 & 0.020 & 0.024 & 0.018 & 0.024 & 0.022 & 0.023 \\
\hline
\end{tabular}


where $n_{k}$ is the target value based on typhoon events, and $\hat{n}_{k}$ the output value of ANN. The learning procedure aims to minimize the total error by making suitable adjustments to the connection weights and biases. The gradient techniques were used herein for this purpose. The error gradient is calculated from the connection weight and bias by propagating the error backwards through the network; the calculation involves simple local computations at nodes in each layer, permitting parallel operations of all nodes in that layer (Rumelhart and Hinton 1986; Sabbir and David 1989).

Table 2 presents the training results. The minimum MSE value is $0.183 \times 10^{-4}$ when the number of hidden nodes, learning rate, and momentum factor are 13, 0.001, and 0.8, respectively. The optimized network structures (figure 1) have 20, 13 , and 5 nodes in the input, hidden, and output layers, respectively. The coefficient of determination $\left(R^{2}\right)$ between the target and ANN output with Manning's $n$ is 0.998 . The training results indicate that output of the ANN with Manning's $n$ is close to that with the target Manning's $n$, and equation (11) yields the optimal weights $\left(W_{j i}^{H}, W_{k j}^{O}\right)$ and biases $\left(\theta_{j}^{H}, \theta_{k}^{O}\right)$.

\subsection{Validation of model}

To examine the real-time updating of the roughness, four typhoon events, including $\mathrm{Hsu}$ and Lee (2000, 2001), were used for model validation. During the validation procedure, for each time-step calculation, first, the dynamic flood routing model is employed with equations (9) and (10) to compute current flow conditions of stage and discharge using current boundary conditions, the previous Manning's $n$, and the previous flow conditions. Then, roughness updating, given by equation (11), is adopted to calculate the current Manning's $n$ from the previous Manning's $n$. The Manning roughness coefficients for the Tamsui River system (table 1) are used as the initial Manning's $n$ at the first run for the four typhoon events, and these values are $0.033,0.032,0.030,0.023$, and 0.023 for the five river segments, respectively. The updated current flow conditions are recalculated again by the dynamic flood routing model with current Manning's $n$. Afterwards, the forecast boundary condition, the new current flow conditions, and Manning's $n$ are used to predict the advance flow conditions by dynamic routing model by equations (3 and 4). Finally, 6-hr leading forecast of water

Table 2. The training result for the optimum structure ANN.

\begin{tabular}{|c|c|c|c|c|c|c|c|c|c|}
\hline \multirow[b]{3}{*}{$\begin{array}{l}\text { Momentum } \\
\text { factor }\end{array}$} & \multirow[b]{3}{*}{$\begin{array}{l}\text { Learning rate } \\
\qquad\left(\times 10^{-4}\right)\end{array}$} & \multicolumn{8}{|c|}{ Mean square error* $\left(\times 10^{-4}\right)$} \\
\hline & & \multicolumn{8}{|c|}{ Node numbers of hidden layer } \\
\hline & & 1 & 5 & 10 & 12 & 13 & 14 & 15 & 20 \\
\hline \multirow[t]{7}{*}{0.7} & 1 & 4.661 & 4.650 & 4.653 & 4.655 & 4.629 & 4.656 & 4.657 & 4.660 \\
\hline & 5 & 2.443 & 2.437 & 2.440 & 2.441 & 2.424 & 2.442 & 2.443 & 2.446 \\
\hline & 9 & 0.447 & 0.444 & 0.448 & 0.449 & 0.440 & 0.450 & 0.451 & 0.454 \\
\hline & 10 & 0.225 & 0.222 & 0.228 & 0.230 & 0.208 & 0.232 & 0.233 & 0.239 \\
\hline & 20 & 0.669 & 0.666 & 0.669 & 0.670 & 0.660 & 0.672 & 0.672 & 0.676 \\
\hline & 50 & 1.334 & 1.330 & 1.333 & 1.334 & 1.322 & 1.336 & 1.336 & 1.334 \\
\hline & 100 & 6.547 & 6.532 & 6.535 & 6.536 & 6.503 & 6.538 & 6.538 & 6.541 \\
\hline \multirow[t]{7}{*}{0.8} & 1 & 6.553 & 6.550 & 6.556 & 6.558 & 6.536 & 6.560 & 6.561 & 6.567 \\
\hline & 5 & 3.740 & 3.738 & 3.743 & 3.746 & 3.724 & 3.748 & 3.749 & 3.754 \\
\hline & 9 & 0.928 & 0.925 & 0.931 & 0.933 & 0.911 & 0.935 & 0.936 & 0.942 \\
\hline & 10 & 0.235 & 0.226 & 0.243 & 0.226 & $0.183^{* *}$ & 0.209 & 0.228 & 0.284 \\
\hline & 20 & 0.576 & 0.574 & 0.579 & 0.581 & 0.560 & 0.584 & 0.585 & 0.590 \\
\hline & 50 & 0.647 & 0.644 & 0.650 & 0.652 & 0.630 & 0.654 & 0.655 & 0.661 \\
\hline & 100 & 1.631 & 1.628 & 1.634 & 1.636 & 1.614 & 1.638 & 1.640 & 1.645 \\
\hline \multirow[t]{7}{*}{0.9} & 1 & 11.437 & 11.211 & 0.141 & 11.150 & 10.986 & 11.158 & 11.162 & 11.183 \\
\hline & 5 & 5.034 & 4.944 & 4.925 & 4.933 & 4.864 & 4.942 & 4.946 & 4.967 \\
\hline & 9 & 2.290 & 2.258 & 2.261 & 2.269 & 2.239 & 2.278 & 2.282 & 2.303 \\
\hline & 10 & 2.250 & 2.230 & 2.260 & 2.280 & 2.190 & 2.290 & 2.300 & 2.330 \\
\hline & 20 & 3.205 & 3.154 & 3.149 & 3.157 & 3.114 & 3.166 & 3.170 & 3.191 \\
\hline & 50 & 7.778 & 7.630 & 7.589 & 7.597 & 7.488 & 7.606 & 7.610 & 7.631 \\
\hline & 100 & 10.522 & 10.315 & 10.253 & 10.262 & 10.112 & 21.027 & 10.274 & 10.295 \\
\hline
\end{tabular}

Note. $*:$ MSE $=\frac{1}{K} \sum_{k=1}^{K}\left(n_{k}-\widehat{n}_{k}\right)^{2} ; * *$ : the minimum MSE. 
stages are utilized to validate the reliability of updating the roughness.

In the model simulation, the upstream and downstream boundary conditions in the four typhoon events are specified using discharge and tidal stages, respectively. The input data in the forecast model include present-time observed and lead-time forecast data. The present-time discharges at the upstream boundaries are obtained from observed runoff hydrographs that are based on realtime observations at the gauge stations, while the downstream boundary condition is obtained from the observed tide stage at river mouth. The 6-hr leading forecast data at the upstream and downstream boundaries are obtained from the Tamsui River flood forecast system (Yen et al. 1998). The model is run to forecast the water stage with updated roughness (equation 11) and fixed Manning's $n$ for $6 \mathrm{hr}$ ahead of typhoon events (i.e., without employing roughness updating).

Figure 5 presents the spatial variation of the maximum water stage from Tamsui River to Dahan River for the four typhoon events. The water stage profiles are utilized to measure the reliability of the initialization of water stage profile for forecasting floods. The results reveal that the water stage profiles that are obtained using updated roughness fit better the observed data than those computed using a fixed Manning's $n$. The reliable water stages forecast profiles can provide flood warnings for any cross-section, including one at a non-gauged station in rivers, enabling appropriate actions during a flood event. Therefore, the dynamic flood routing model that is based on roughness updating can reliably provide flow conditions.

Figure 6 displays the time-varying Manning's $n$ with roughness updating and water stage changes for typhoon Xangsane. In figure 6(e), obtained at the Shizitou gauge station, for example, at the beginning of flood routing $(t=0 \mathrm{hr})$, the computed and observed water stages are the same. At the next time point $(\mathrm{t}=1 \mathrm{hr})$, the computed water stage is lower than the observed water stage, and Manning's $n$ with roughness updating will be revised upwards to correct the computed value towards the observed value. When the computed water stage is higher than the observed water stage, the Manning's $n$ value is revised downward to reduce the computed values to the observed values. The same computed water stage correction
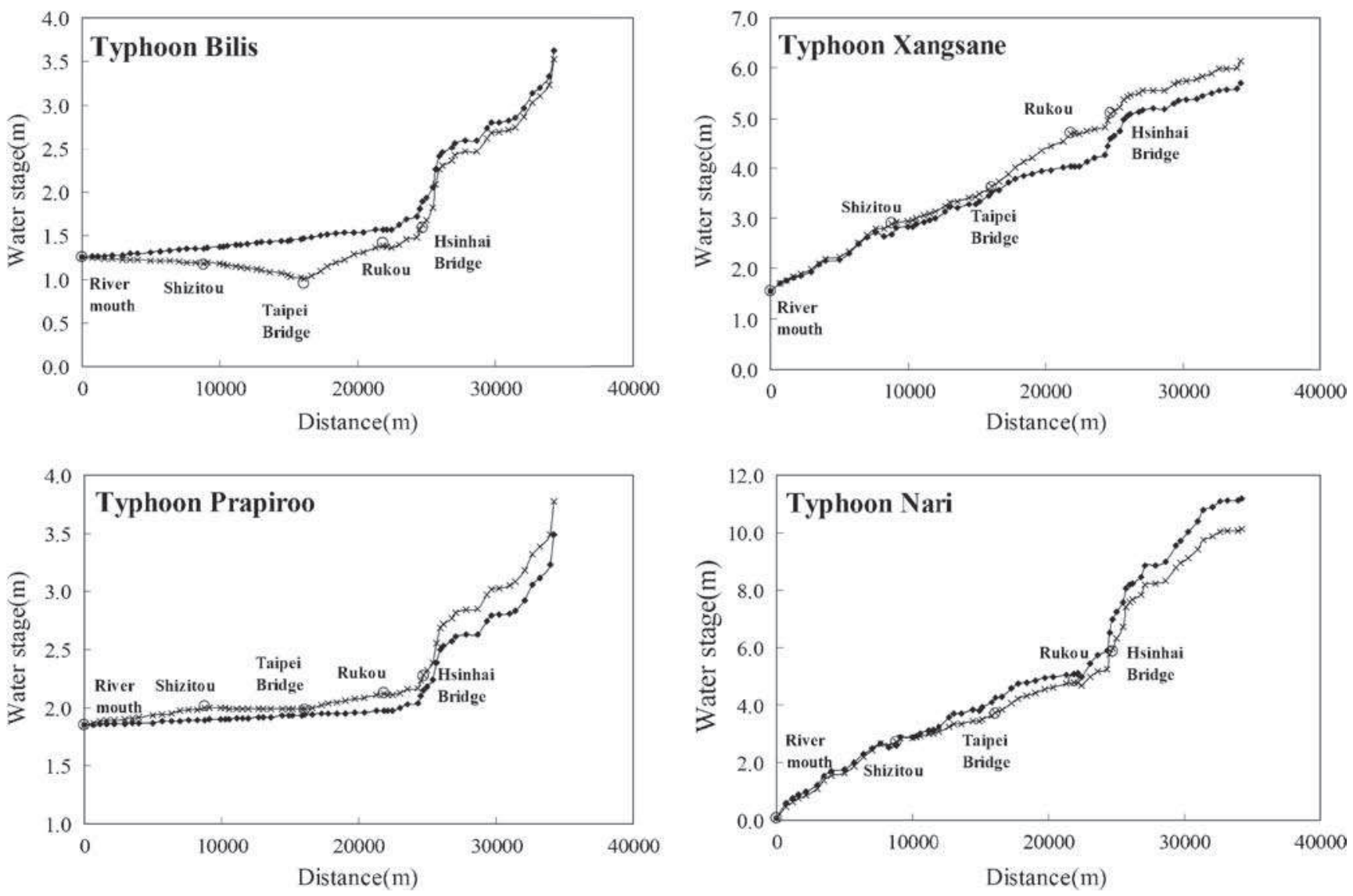

○ Observed $*$ with real-time roughness updating $\quad \bullet$ without real-time roughness updating

Figure 5. The maximum stage profiles during the four typhoon events in the Tamsui River-Tahan Creek. 


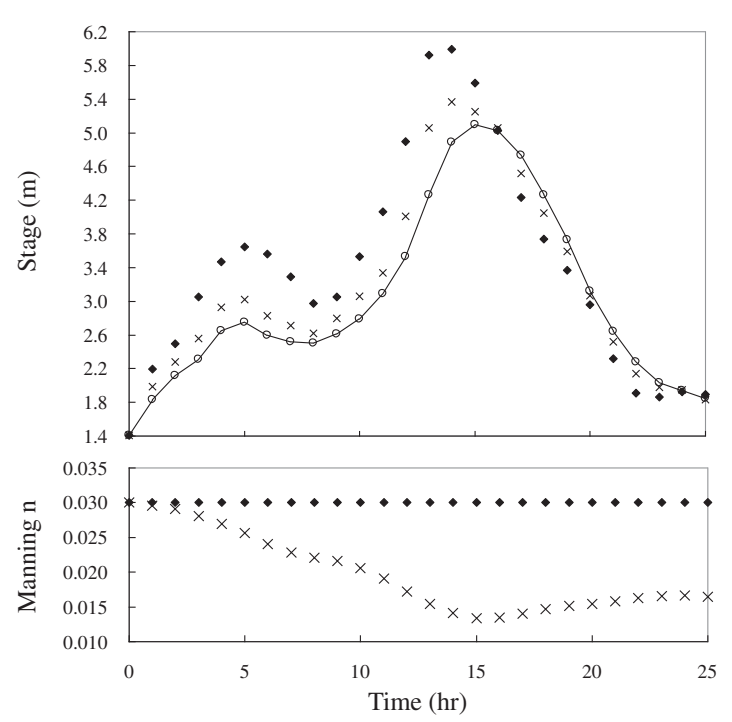

(a) Hsinhai Bridge

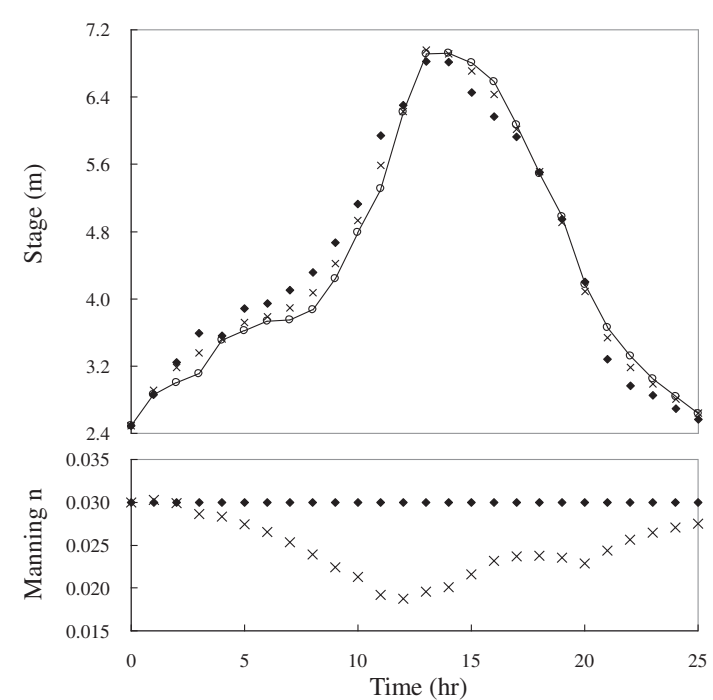

(b) Chungcheng Bridge

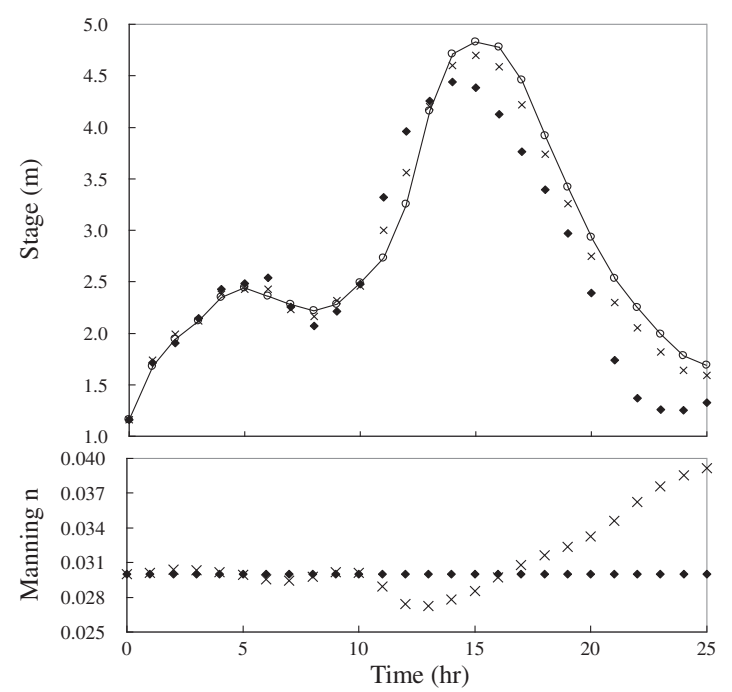

(c) Rukou

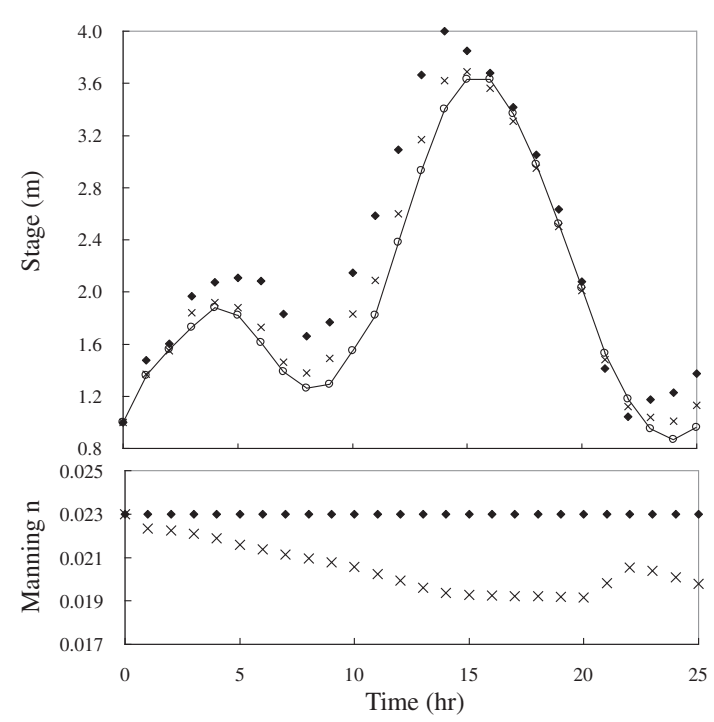

(d) Taipei Bridge

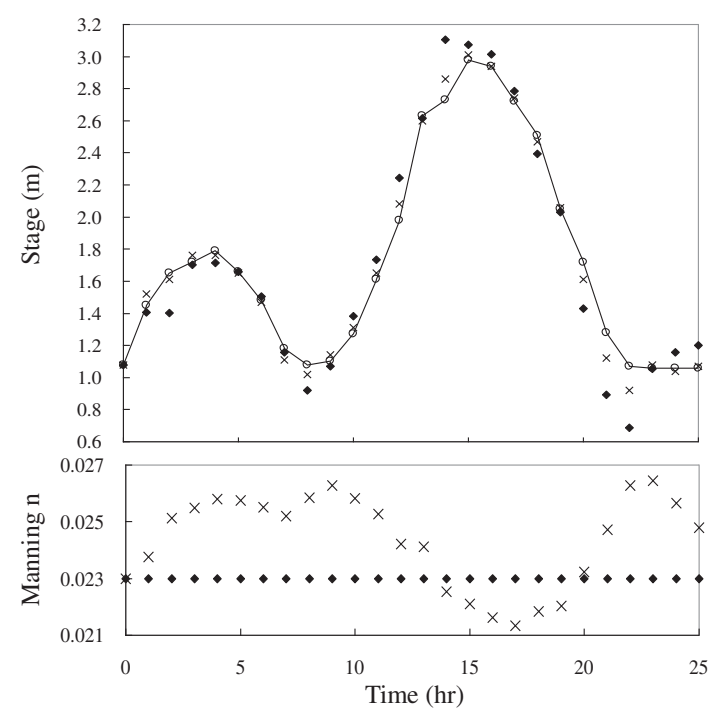

(e) Shizitou

- Observed

${ }^{-x}$ - with real-time roughness updating

- without real-time roughness updating

- Varying Manning $n$ with roughness updating

- Fixed Manning $n$

Figure 6. The relationship of time-varying Manning's $n$ with roughness updating and water stage changes for typhoon Xangsane. 
can be found in figure 6 for the Hsinhai Bridge, Chungcheng Bridge, Rukou, and Taipei Bridge. The results demonstrate that the roughness updating in the river hydraulic model provides a new Manning's $n$ with the observed depth and drag coefficient, which are used in subsequent forecasting.

Since channel routing is deterministic, the errors are introduced by the boundary conditions (upstream, downstream, and lateral inflows) and roughness. Consequently, roughness influences the water
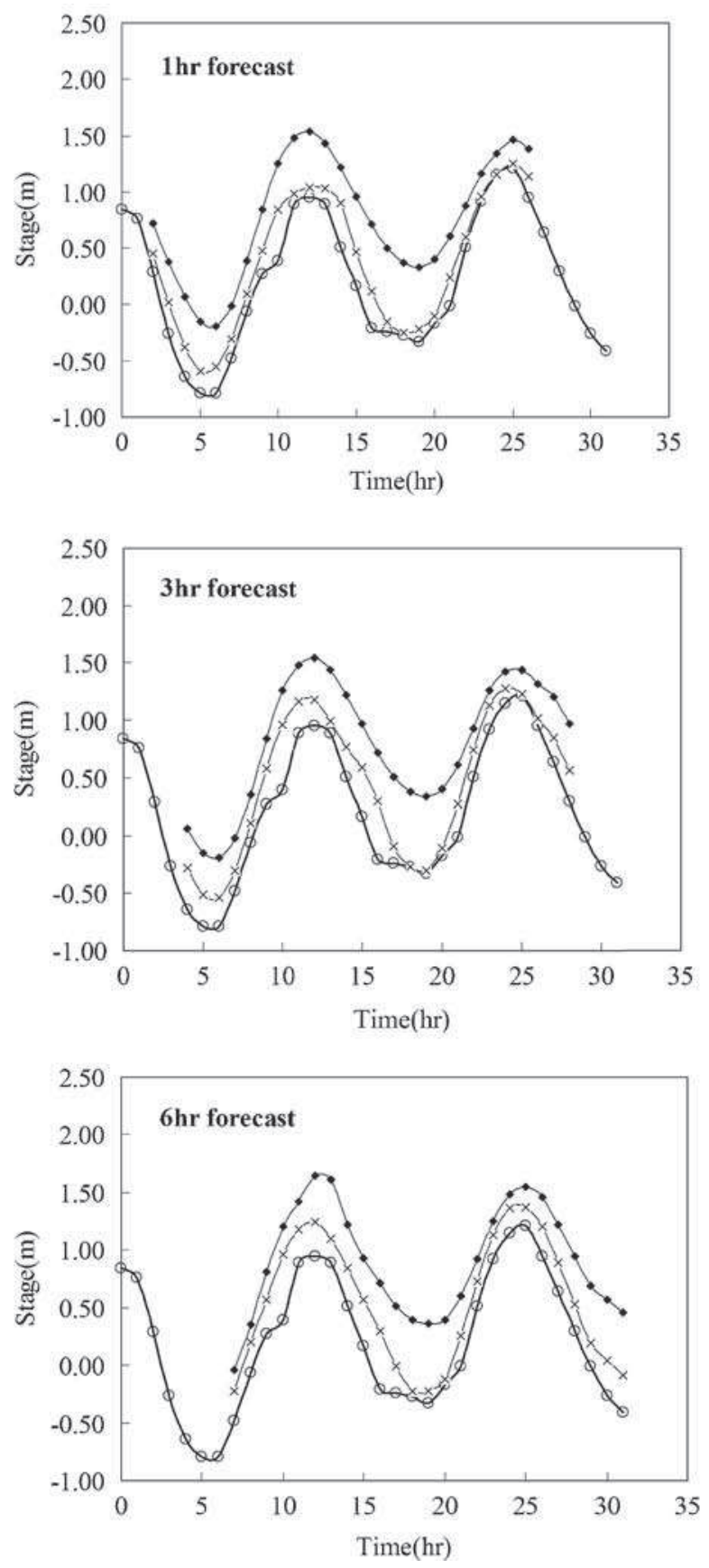

(a) Typhoon Bilis stage and storage in the river segment. To evaluate the conservation of mass in a river segment for roughness updating, the relative error $\left(R_{e}\right)$ (the ratio of non-conservative discharge, including the net outflow and the rate of change in storage, to the inflow discharge) was adopted. The $R_{e}$ of zero indicates that mass is conserved in the river segment. The mean relative errors in the four typhoon events are $7.91 \times 10^{-4}, 2.32 \times 10^{-4}, 3.35 \times 10^{-4}$, and $8.70 \times 10^{-4}$ respectively for Dahan River,
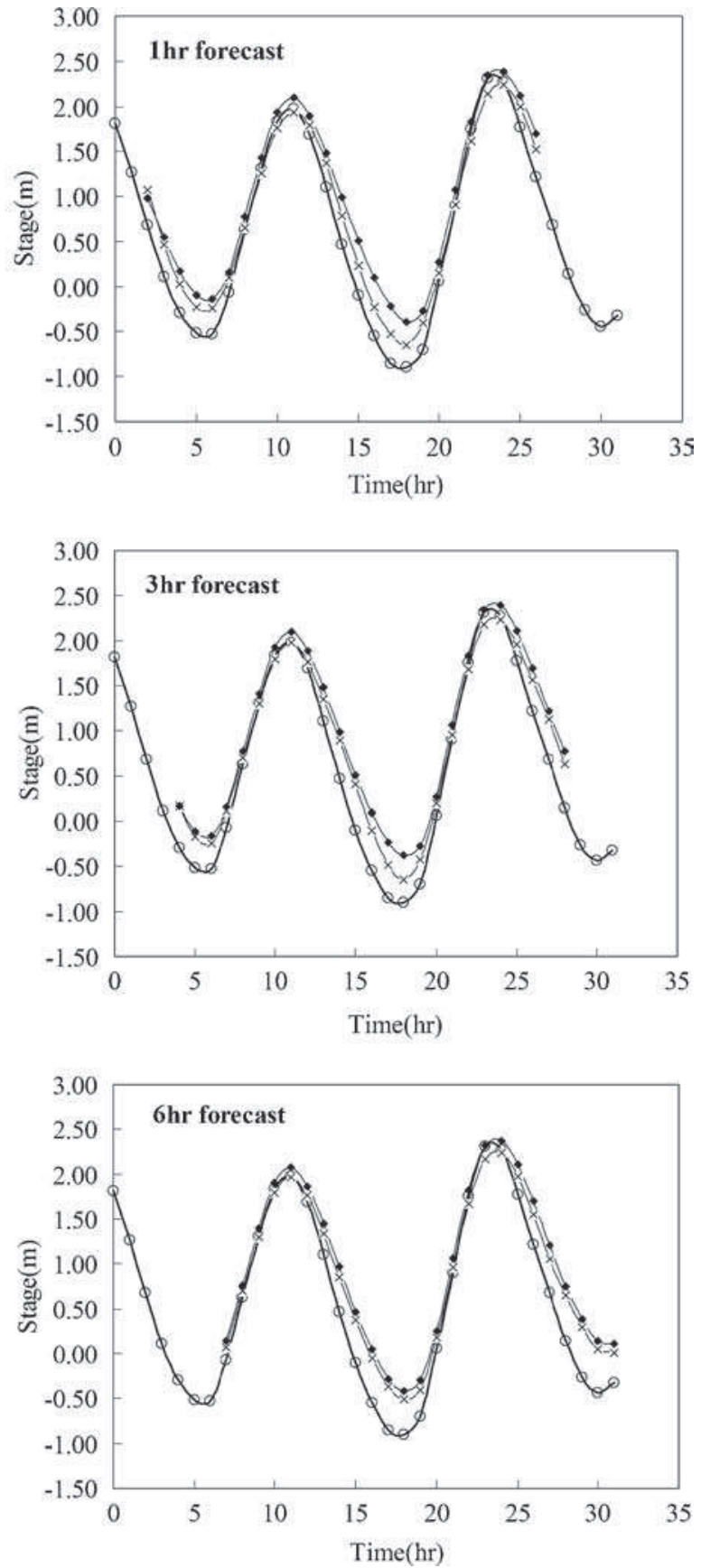

(b) Typhoon Prapiroo

$\circ$ Observed $*$ with real-time roughness updating $\rightarrow$ without real-time roughness updating

Figure 7. The forecasted water stage hydrographs of four typhoon events in Taipei Bridge with various lead times. 

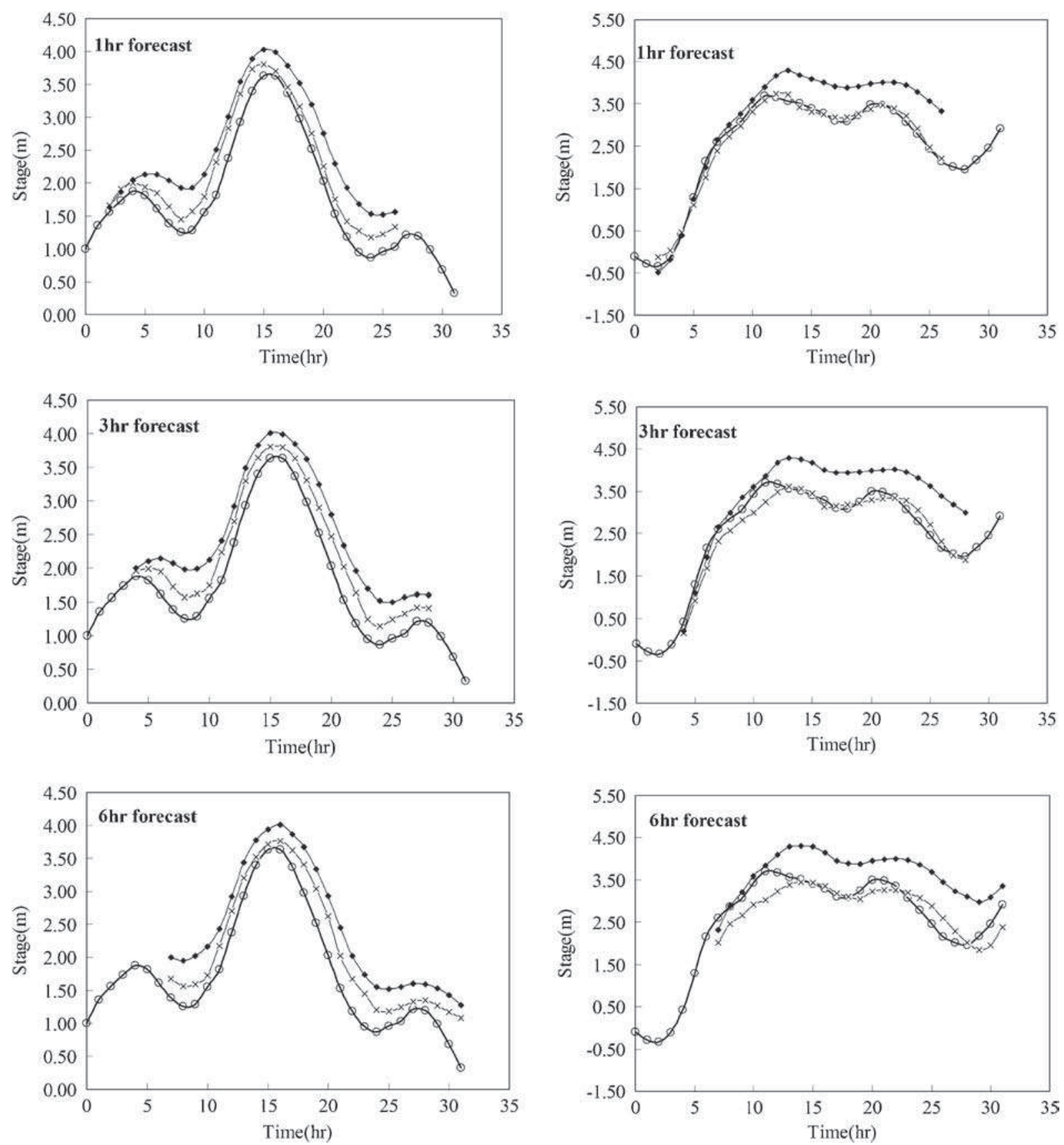

(c) Typhoon Xangsane

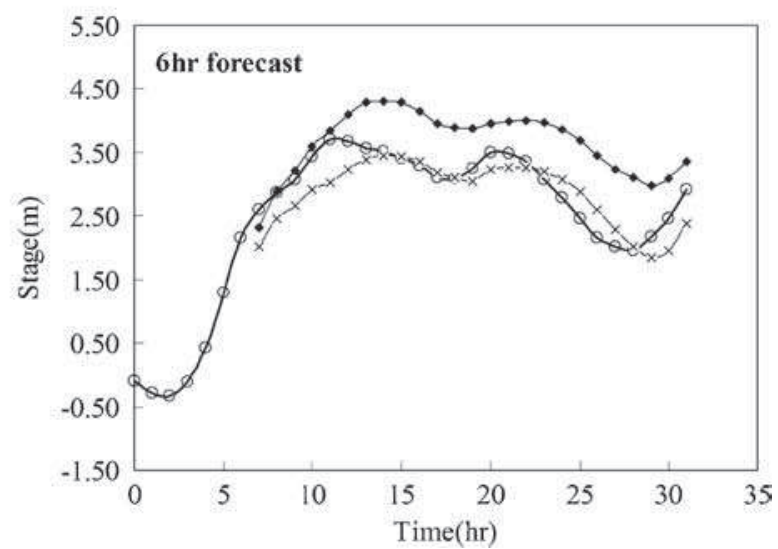

(d) Typhoon Nari

- Observed $*$ with real-time roughness updating

Figure 7. (Continued.)

Xindian River, Rukou to Shizitou, and Shizitou to River mouth. These values show that the error that is introduced from the numerical methods is negligible, and roughness updating maintains the conservation of mass.

\subsection{Forecasting water stage}

Figure 7 plots the differences between the observed and computed forecast hydrographs of the water stage; also shows computed values with and without roughness updates. The water stage forecast hydrographs at Taipei Bridge are displayed for lead times of one, three and six hours during four typhoon events. The analytical results reveal that forecast hydrograph of water stage with real-time roughness updating is similar to the observed water stage hydrograph, and so yields a better prediction of the water stage. Furthermore, the correcting capacity of the model reduces the error of forecasts up to $6 \mathrm{hr}$. Flood routing with the real-time roughness updating better predicts the peak water stage, 
with an error in the timing of the peak water stage of less than an hour.

The root mean square errors (RMSE) between the observed and forecasted water stages are calculated to evaluate model performance. The RMSE can be written as:

$$
\operatorname{RMSE}=\left\{\frac{1}{N}\left[\sum_{1}^{N}(Y-\widehat{Y})^{2}\right]\right\}^{1 / 2}
$$

where $\hat{Y}$ is the computed water depth; $Y$ the observed water depth, and $n$ the total number of observed water depths.

Figure 8 compares the RMSE values of the four typhoon events of interest - Typhoon Bilis, Prapiroo, Xangsane and Nari - for predictions 1-6 hrs with and without roughness updating. Generally, a smaller RMSE indicates a better model. The RMSE of the water stage increases with lead time. It is $0.208,0.253$ and $0.293 \mathrm{~m}$ for one, three, and

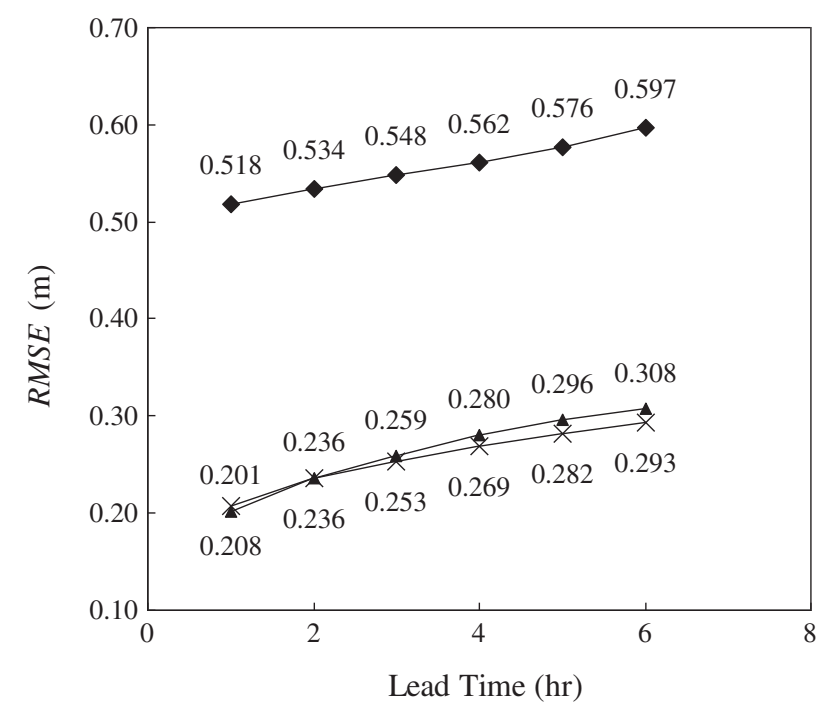

-x- with real-time roughness updating

$\bullet$ without real-time roughness updating

- roughness updating with optimization method [Hsu et al. 2006]

Figure 8. Mean RMSE of four typhoon events with 6-hr lead time. six hours ahead with roughness updating. However, the RMSE without roughness updating is around double that with roughness updating. When roughness is updated using the optimization method of Hsu et al. (2006), the RMSE is only slightly higher. The RMSE obtained using dynamic flood routing model with roughness updating did not increase significantly with lead time. The mean CPU times without roughness updating, with roughness update and the optimization method (Hsu et al. 2006) and with roughness updating for each timestep forecast in the forecast for Tamsui River are about $0.630,0.865$ and $0.736 \mathrm{sec}$, respectively, using an Intel(R) Core(TM) i7-3770 CPU @3.4GHz. These results show real-time roughness updating effectively and improves the accuracy of flood forecasting.

A sensitivity analysis can be carried out to evaluate how a given system output is modified in response to system input variables and the results can elucidate the effects of input variables on model performance. In the sensitivity runs herein, the input variables - the previous-time Manning's $n$, the difference between computed and observed water depths, computed water depths and computed discharges - are eliminated one at a time, yielding various RMSE values. The highest RMSE values is obtained when the input variable to which the output is most sensitive is eliminated.

Table 3 presents the RMSE values for different input variables at various lead times. The RMSE values indicate that eliminating the previous-time Manning's $n$ yields an accurate forecast $1 \mathrm{hr}$ ahead but less accurate forecasts $2-6 \mathrm{hr}$ ahead. Eliminating the difference between computed and observed water depths caused the RMSE of the water stage to increase slightly with lead time. Eliminating the computed water depth causes the RMSE values show that they have a very slight effect on the forecast water stage. When the computed discharge is eliminating, forecasts are accurate up to $6 \mathrm{hrs}$ ahead. The previous-time Manning's $n$ affects more factors than any of the other three input variables and seriously affects the updating of roughness.

Table 3. The sensitivity analyses using RMSE values for different lead times.

\begin{tabular}{lcccc}
\hline & \multicolumn{4}{c}{ Eliminating input variables } \\
\cline { 2 - 5 } Time & $\begin{array}{c}\text { Computed water } \\
\text { depths }\end{array}$ & $\begin{array}{c}\text { Difference of } \\
\text { water depths }\end{array}$ & $\begin{array}{c}\text { Computed } \\
\text { discharges }\end{array}$ & $\begin{array}{c}\text { Previous-time } \\
\text { Manning's } n\end{array}$ \\
\hline 1 & 0.2113 & 0.2133 & 0.2103 & 0.2001 \\
2 & 0.2396 & 0.2416 & 0.2379 & 0.2428 \\
3 & 0.2552 & 0.2577 & 0.2539 & 0.2757 \\
4 & 0.2702 & 0.2726 & 0.2689 & 0.3018 \\
5 & 0.2835 & 0.2866 & 0.2826 & 0.3229 \\
6 & 0.2944 & 0.2991 & 0.2932 & 0.3408 \\
\hline
\end{tabular}




\section{Conclusions}

The study developed a one-dimensional river hydraulic model for forecasting flash floods at Tamsui River in Taiwan. The Manning's coefficient is considered to vary over time and an ANN-based method is used to estimate its value. Four typhoon events were utilized to analyze the forecasting of the water stage using the model. The model is run to forecast the water stage with roughness updating and a fixed Manning's $n$ for lead time of $1-$ $6 \mathrm{hr}$. The results indicate that ANN successfully updates the nonlinear Manning's $n$ at each timestep of the flood routing process, and satisfactorily forecasts water stages during typhoon events with a lead time of up to $6 \mathrm{hr}$. Sensitivity analysis has revealed that the previous-time Manning's $n$ significantly influences the factors that affect the roughness updating. Hence, a flood forecast model with time-varying Manning's $n$ with satisfactory data is an efficient tool for assisting the managers in decision-making during typhoons.

\section{References}

Amein M and Fang C S 1970 Implicit flood routing in natural channel; J. Hydraul. Div. 96 2481-2500.

Bodri L and Cermá V 2000 Prediction of extreme precipitation using a neural network: Application to summer flood occurrence in Moravia; Adv. Eng. Software 31 311-321.

Chen H, Yang D, Hong Y, Gourley J J and Zhang Y 2013 Hydrological data assimilation with the ensemble squareroot-filter: Use of streamflow observations to update model states for real-time flash flood forecasting; $A d v$. Water Resourc. 59 209-220.

Chen S M, Wang Y M and Tsou I 2013 Using artificial neural network approach for modelling rainfall-runoff due to typhoon; J. Earth Syst. Sci. 122(2) 399-405.

Chow V T 1997 Open-Channel Hydraulics; McGraw-Hill Book Company.

Chow V T, Maidment D R and Mays L W 1998 Applied Hydrology, McGraw-Hill Book Company.

Haykin S 1999 Neural network: A comprehensive foundation, 2nd edn, Prentice Hall.

Hsu M H and Lee T H 2000 Maintenance and further development of flood forecasting system model for Tamsui River Basin (I) Technical Report; Water Resources Agency of the Ministry of Economic Affairs (in Chinese).

Hsu M H and Lee T H 2001 Maintenance and further development of flood forecasting system model for Tamsui River Basin (II) Technical Report; Water Resources Agency of the Ministry of Economic Affairs (in Chinese).

Hsu M H, Fu J C and Liu W C 2006 Dynamic routing model with real-time roughness updating for flood forecasting; J. Hydraul. Eng. 132(6) 605-619.

Hsu M H, Lin S H, Fu J C, Chung S F and Chen A S 2010 Longitudinal stage profiles forecasting in rivers for flash floods; J. Hydrol. 388 426-437.
Karahan H, Guraralan G and Geem Z 2013 Parameter estimation of the nonlinear Muskingum flood-routing model using a hybrid harmony search algorithm; J. Hydraul. Eng. 18(3) 352-360.

Khatibi R, Ghorbani M A, Kashani M H and Kisi O 2011 Comparison of three artificial intelligence techniques for discharge routing; J. Hydrol. 403 201-212.

Leedal D, Weerts A H, Smith P J and Beven K J 2013 Application of data-based mechanistic modelling for flood forecasting at multiple locations in the Eden catchment in the National Flood Forecasting System (England and Wales); Hydrol. Earth Syst. Sci. 17 177-185.

Li Y, Ryu D, Western W A, Wang Q J, Robertson E D and Crow T W 2014 An integrated error parameter estimation and lag-aware data assimilation scheme for real-time flood forecasting; J. Hydrol. $5192722-2736$.

Liu W C, Chen W B, Hsu M H and Fu J C 2010 Dynamic routing modeling for flash flood forecast in river system; Natural Hazards 52(3) 519-537.

Marier H R and Dandy G C 2000 Neural networks for the prediction and forecasting of water resource variables: A review of modeling issues and application; Environmental Modeling and Software 15 101-124.

Neal C J, Atkinson M P and Hutton W C 2012 Adaptive space-time sampling with wireless sensor nodes for flood forecasting; J. Hydrol. 414 136-147.

Park D and Markus M 2014 Analysis of a changing hydrologic flood regime using the variable infiltration capacity model; J. Hydrol. 515 267-280.

Preissman A 1961 Propagation of translatory waves in channels and rivers; First Congress of French Association for Computation, Grenoble, September 14-16; Proceedings, A.F.C.A.L., pp. 433-442 (in French).

Rumelhart D E and Hinton G E 1986 Learning representations by back-propagation error; Nature $\mathbf{3 2 3} 533-536$.

Ryszard T, Rituparna C and Nabendu C 2014 Exploring Neural Networks with C\#; Taylor \& Francis.

Sabbir S R and David A D 1989 Learning and optimization of machining operations using computing abilities of neural networks; IEE Trans. System, Man. and Cybernetics 16 299-314.

Sene K 2013 Flash Floods: Forecasting and Warning; Springer.

Song X M, Kong F Z and Zhu Z X 2011 Application of Muskingum routing method with variable parameters in ungauged basin; Water Sci. Eng. 4(1) 1-12.

Uzlu E, Kankal M, Akpinar A and Dede T 2014 Estimates of energy consumption in Turkey using neural networks with the teaching-learning-based optimization algorithm; Energy 75 295-303.

Villiers J and Barnard E 1992 Backpropagation neural nets with one and two hidden layers; IEEE Trans. Neural Networks 4 136-141.

Weerts A H, Winsemius H C and Verkade J S 2011 Estimation of predictive hydrological uncertainty using quantile regression: Examples from the National Flood Forecasting System (England and Wales); Hydrol. Earth Syst. Sci. 15 255-265.

Xu X Z and Li J Y 2002 Short-term inflow forecasting using an artificial neural network model; Hydrol. Process. 16 2423-2439.

Yen C L, Lee T H, Wang R Y, Young D L and Hsu M H 1998 Research and development of flood forecasting system model for Tamsui River basin; Technical Report, Water Resources Agency of the Ministry of Economic Affairs (in Chinese). 